\title{
Treatment of malignant meningitis in retinoblastoma
}

\author{
CLARE E. STANNARD*, R. SEALY*, D. SEVEL†, AND F. A. BRINTON \\ From the Departments of *Radiotherapy, †Ophthalmology, and $\ddagger$ Obstetrics and Gynaecology (Cytology Service), Groote \\ Schuur Hospital and University of Cape Town, South Africa
}

It has long been known that retinoblastoma can spread along the optic nerve and into the spinal cord via the subarachnoid space (Knapp, I869).

Merriam (1950) described I 7 necropsies on children with retinoblastoma in three of whom there was widespread involvement of the subarachnoid space of the spinal cord by the retinoblastoma. In two of these cases, the tumour cells were detected in the cerebrospinal fluid (CSF) before death.

Intracranial extension of advanced retinoblastoma is a common occurrence and was found to be the only site of tumour dissemination in I I out of 24 necropsies reported on by Reese (1963). Death in the remaining I 3 cases was due to haematogenous spread.

Berkeley, Fuller, Sears, and Tapley (1967) stated that intracranial spread of retinoblastoma represented advanced and incurable disease for which only palliative treatment in the form of oral endoxan and intrathecal methotrexate could be offered. They found that this was effective in relieving symptoms, clearing the CSF of tumour cells, and possibly increasing the survival time of these patients.

In the following case reports it can be seen that the diagnosis of malignant meningitis may be suspected on clinical examination, but is confirmed by the demonstration of malignant cells in the CSF.

The fluid is processed as soon as possible after withdrawal. If there is likely to be any delay at all in transit, it is first fixed with an equal quantity of 50 per cent ethyl alcohol. Where there is a large quantity of fluid, it is first spun down. When a button forms, the supernatant liquid is gently removed to leave about $\mathrm{I} \mathrm{ml}$. The cells are then re-suspended and passed through a Millepore filter or a cytocentrifuge. Where no button forms or where the volume of fluid is less than $1 \mathrm{ml}$, the whole specimen is either filtered or cytocentrifuged. At least four slides are prepared from the sample, fixed in 96 per cent ethyl alcohol and stained by the Papanicolaou method.

The cytological aspects of retinoblastoma have been described by Wieczorek (1964), Ifekwunigwe, Pulvertaft, and Williams (1966), and Spriggs and Boddington (1968). Wieczorek mentions a high

Address for reprints: C. E. Stannard, Department of Radiotherapy, Groote Schuur Hospital, Observatory, Cape Town, Cape, South Africa nucleocytoplasmic ratio and prominent nucleoli, while Spriggs and Boddington describe one case in their series showing abundant, small, poorlydifferentiated cells forming clusters. Ifekwunigwe demonstrated the cells of retinoblastoma by means of phase-contrast.

The treatment of malignant meningitis is similar to the prophylactic treatment of the central nervous system in acute lymphoblastic leukaemia with cranial irradiation and intrathecal methotrexate. In this series, there is one survivor.

No cases of retinoblastoma treated this way can be found in the literature.

\section{Material and methods}

During the period February 1972 to February 1974, 22 patients with retinoblastoma were assessed at the Ocular Tumour Clinic at Groote Schuur Hospital. The majority of these patients presented with either optic nerve involvement or bilateral disease. Six of these patients were found to have malignant cells in the CSF, though only two had the clinical signs of meningitis. Five of these six patients were known to have had optic nerve involvement. An attempt was made initially to treat the meningitis with intrathecal methotrexate $\left(12 \mathrm{mg} / \mathbf{M}^{2}\right)$ and later with whole head irradiation when the meningitis recurred.

Three of the children treated this way died approximately 6 months after the beginning of the treatment, although they did achieve clinical and cytological remission for a period. The temporary success of this regime suggested the more aggressive approach which was adopted in the other cases described.

CASE I

A three-year-old African boy presented at another hospital with pulmonary tuberculosis in November $197 \mathrm{I}$. The following February, a leucocoria of the right eye was noticed and an enucleation was performed. Histological studies showed the features of a retinoblastoma with extension of the tumour along the optic nerve. The patient was referred to the Ocular Tumour Clinic at Groote Schuur Hospital and was found to be well systemically.

Chest $x$ ray showed collapse and consolidation with destruction of the right upper lobe in keeping with tuberculosis. No lung metastases were noted. Orbital $x$ rays showed an enlarged right optic foramen. Examination under general anaesthesia (EUA) showed a normal 
left eye, but in the right socket there was a firm posterior orbital mass. This was biopsied and the histological studies showed a retinoblastoma.

The patient continued the antituberculous therapy that he had been receiving for the previous 3 months. He also received deep $x$-ray therapy to the right orbit $(3520 \mathrm{r} / 26$ days) together with intravenous endoxan (three fortnightly injections of $50 \mathrm{mg} / \mathrm{kg}$ ).

EUA 8 weeks after the completion of treatment showed a contracted socket but no orbital mass. The left eye was again normal.

Two months later the patient became drowsy and was found to have neck stiffness and clonic movements of his arms and legs. Examination of the CSF showed clusters of cells highly suspicious of malignancy as well as scanty inflammatory cells. Brain scan showed an area of increased uptake in the region of the optic chiasma. EUA showed a raised white nodule on the temporal side of the left disc. The patient was then treated with intrathecal methotrexate $\left(12 \mathrm{mg} / \mathrm{M}^{2}\right.$ weekly $\left.\times 6\right)$ and intravenous endoxan ( $30 \mathrm{mg} / \mathrm{kg}$ fortnightly). His general condition improved, the CSF became clear of malignant cells, but he lost the sight in his left eye. A further EUA showed peripapillary oedema and slight disc pallor, and it was assumed that the left optic nerve was also involved by the tumour.

Three weeks after the methotrexate was stopped he again became drowsy and ataxic. There was no neck stiffness and no malignant cells were found in the CSF. He was treated with deep $x$-ray therapy to the whole head (3000 $\mathrm{r} / 3 \mathrm{I}$ days) together with weekly intrathecal methotrexate, and fortnightly intravenous injections of endoxan and vincristine.

The patient again recovered and remained well for 2 months, but then developed headaches and neck stiffness. $x$ ray of the skull showed signs of raised intracranial pressure. He was treated with endoxan but continued to deteriorate and he died in April 1973, 14 months after the initial diagnosis and 6 months after the initial treatment for malignant meningitis.

\section{CASE 2}

A nine-year-old African boy was seen at another hospital in October 1972, complaining of 'progressive swelling of the right eye' for 10 months. The eye was enucleated and the histology showed a retinoblastoma with infiltration of the optic nerve.

The tumour recurred locally, and in November 1972 he was referred to the Ocular Tumour Clinic at Groote Schuur Hospital. On examination, the entire right orbit was filled by a mass and the eyelids were oedematous and painful. The left eye was normal and there was no neck stiffness. The CSF showed atypical cells (Figure) and the brain scan showed increased uptake behind the right orbit, compatible with spread of the tumour. Tomographs

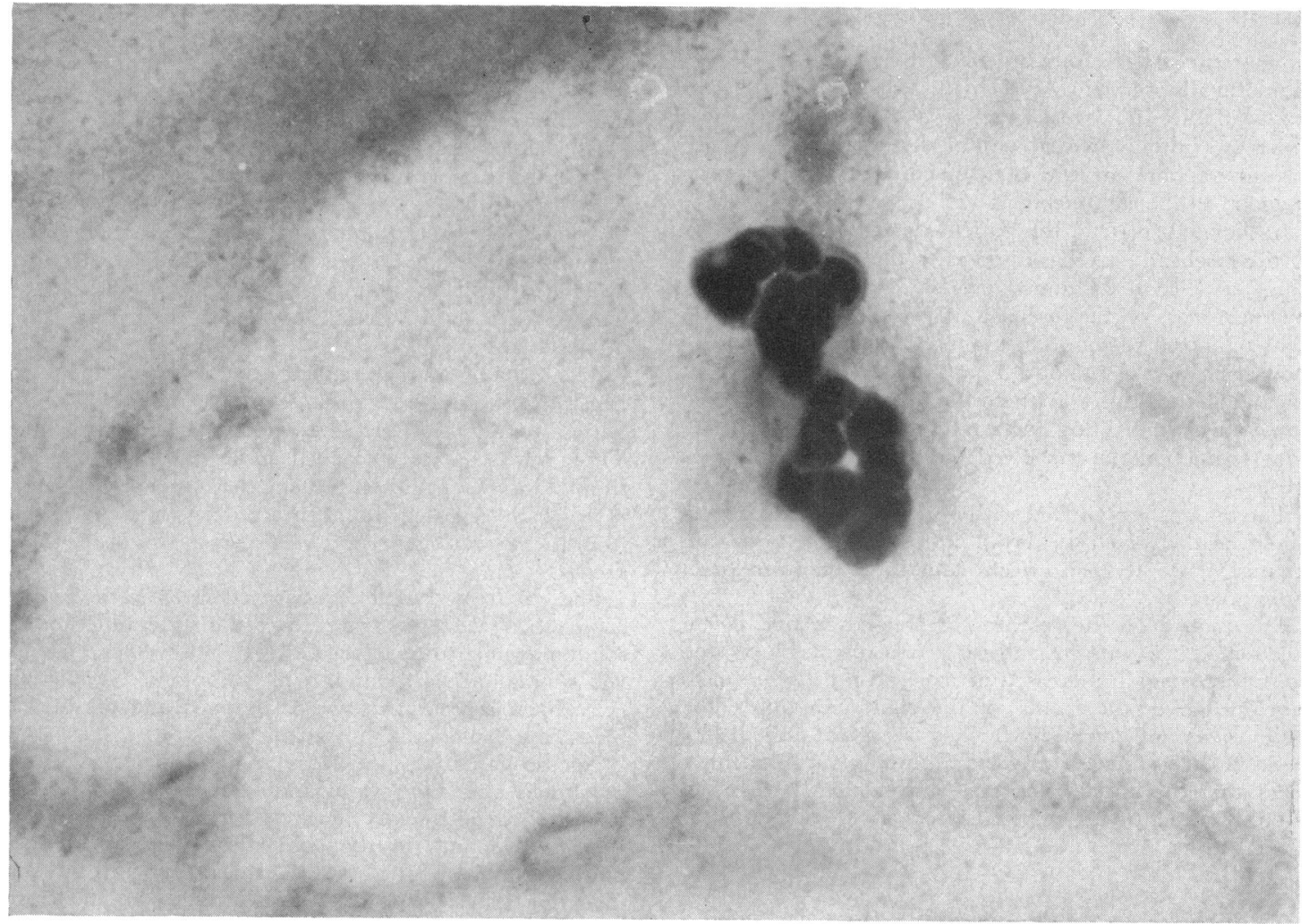


of the optic canal showed marked enlargement of the right optic foramen and the optic canal throughout its length.

The patient was initially treated with intravenous endoxan, but as the tumour continued to grow rapidly, he was treated with deep $x$-ray therapy to the right orbit ( $4150 \mathrm{r} / 33$ days), intravenous vincristine ( $0.5 \mathrm{mg}$ weekly), and intrathecal methotrexate $\left(12 \mathrm{mg} / \mathrm{M}^{2}\right.$ weekly for 6 weeks). He responded remarkably well, the tumour regressing completely, and the CSF becoming clear of malignant cells after 4 weeks. Brain scan at this stage also showed tumour regression.

He was discharged and returned for follow-up 6 weeks later. Although symptomatically well, with no clinical evidence of tumour, the CSF showed numerous clusters of malignant cells. He was treated again with intrathecal methotrexate and deep $x$-ray therapy to the whole head was started. He then developed weakness of the right arm and leg and at the second intrathecal injection, there was evidence of a spinal block. $X$ rays of the dorso-lumbar spine showed attenuation of the right pedicles of the twelfth thoracic and first lumbar vertebrae. Deep $x$-ray therapy to his head was discontinued and the spine was irradiated. He then developed glands in the right groin and a swelling of the left supraorbital ridge. Treatment was abandoned and the patient died in March 1973, I5 months after the initial symptoms and 5 months after the initial treatment for malignant meningitis.

\section{CASE 3}

A two-year-old African boy had the right eye enucleated at another hospital in April 1972. No histological study was available. In August 1972, he had a local recurrence which was initially treated with methotrexate, but as there was no response, he was then given deep $x$-ray therapy (3 ooo $r$ ) to the right orbit.

In November 1972, the patient developed recurrences on the forehead and was referred to the Ocular Tumour Clinic at Groote Schuur Hospital. There was a large fluctuant mass on the forehead and a hard mass over the right temporal region. The right socket and the left eye showed no sign of tumour. The CSF showed an atypical cell and on the brain scan there was increased uptake in the frontal area indicating metastatic spread. The aspirate from the fluctuant lump showed undifferentiated malignant cells.

The patient was treated with deep $x$-ray therapy to the whole head (3000 $\mathrm{r} / 43$ days), intrathecal methotrexate (12 $\mathrm{mg} / \mathbf{M}^{2}$ weekly for Io weeks), and intravenous endoxan (30 $\mathrm{mg} / \mathrm{kg} \times 4)$.

The masses on the forehead decreased in size. Seven weeks after the cytotoxic therapy was discontinued, the frontal mass again increased in size and a $6 \times 5 \mathrm{~cm}$ mass developed over the ramus of the right mandible. The patient was not given any further treatment and died 5 weeks later; I 3 months after the beginning of treatment, 2 years after the initial symptoms, and 5 months after the initial treatment with methotrexate.

\section{CASE 4}

A two-year-old African girl presented in March 1973, with gross tumour filling both eyes. The right eye was enucleated and histological studies confirmed a retinoblastoma. As the intraocular contents of the left eye were replaced by tumour tissue, it was also enucleated. Histological studies of both eyes showed an endophytic type of retinoblastoma, with infiltration of the right optic nerve only. The CSF showed a single cluster of degenerate atypical cells and the brain scan showed increased uptake on the left side over the supraorbital and retro-orbital regions.

The patient was treated with intrathecal methotrexate (12 $\mathrm{mg} / \mathrm{M}^{2}$ for 6 weeks), intravenous endoxan (three fortnightly injections of $30 \mathrm{mg} / \mathrm{kg}$ ), and deep $x$-ray therapy to the whole head ( $1785 \mathrm{r}$ midplane over $2 \mathrm{I}$ days) followed by planned fields to the orbits ( $1625 \mathrm{r} / 14$ days). The brain scan after treatment was normal, and the CSF became clear.

She remained well for 8 months but then had two generalized convulsions. There was no clinical evidence of a recurrence, the brain scan was normal, and the CSF was clear of malignant cells. She was given I-(2-chloroethyl)-3-cyclohexyl-1-nitroso-urea (CCNU) 10o $\mathrm{mg} / \mathrm{M}^{2}$ orally and continues to receive this every 2 months. She has remained well since and the CSF has now been clear for 20 months.

\section{CASE 5}

A three-year-old Cape coloured girl presented in February 1974 with a left buphthalmos which had been progressive for one year after the appearance of a white disc in the eye. The eye was enucleated and histological studies showed that it was filled with retinoblastoma which had also infiltrated the choroid, the sclera, and the optic nerve up to the line of excision.

Clusters of highly atypical cells were seen in the CSF. The brain scan was normal. She was treated with deep $x$-ray therapy to the whole head ( $2500 \mathrm{r} / 32$ days) followed by planned fields to the left orbit ( $3240 \mathrm{r} / 26$ days), thus giving a maximum tumour dose of $4050 \mathrm{r} / 7 \mathrm{I}$ days. She also received CCNU $50 \mathrm{mg}$ orally every 6 weeks, together with six intrathecal injections of methotrexate (12 $\mathrm{mg} / \mathbf{M}^{2}$ ) at weekly intervals.

The CSF became clear, but about 3 weeks later, she became irritable, had neck stiffness, and developed a flaccid paralysis of the legs and a hypotonic bladder. There vrere scanty atypical cells in the CSF, the bone scan showed increased uptake in the upper lumbar spine, and a myelogram revealed an intramedullary mass extending from the level of the second lumbar vertebra to the sacral sac.

She was treated with deep $x$-ray therapy to the lumbar spine (400o $\mathrm{r} / 27$ days) and recovered bladder function and some movements in the legs. She then developed a $2 \mathrm{~cm}$ left submandibular gland, which contained malignant cells. Further treatment was abandoned and she died of bronchopneumonia in July 1974 .

Necropsy findings showed tumour infiltration of the arachnoid over the frontal and temporal lobes, tumour deposits around the medulla, cerebellum, and attached to the whole length of the cord dura. There were also paravertebral tumour masses associated with but not involving the eleventh and twelfth dorsal and first and second lumbar vertebrae. The left orbit volume treated showed no neoplasm. 
CASE 6

A 16-month-old African boy presented in February 1974 at another hospital with recent swelling of the right eye and a white spot, which had been present since birth.

An enucleation was performed and histological studies showed an eye filled with retinoblastoma which had also infiltrated the sclera, muscular tissue, and the optic nerve as far as the line of excision. The CSF and the brain scan were normal. EUA showed a hard tumour palpable in the posterior part of the socket. This was biopsied and the histological studies showed a recurrence of retinoblastoma.

He was treated with deep $x$-ray therapy to the right orbit (396o $\mathrm{r} / 29$ days) and intravenous endoxan (three fortnightly injections of $30 \mathrm{mg} / \mathrm{kg}$ ). This was followed by exenteration of the right orbit and histological studies of the specimen showed no recurrence of the tumour.

Two weeks after exenteration he became irritable and developed neck stiffness. Lumbar puncture revealed xanthochromic and blood-stained fluid, in which there were poorly differentiated malignant cells and mitotic figures. Brain scan showed signs of intracranial spread. He was treated with weekly intrathecal methotrexate ( $12 \mathrm{mg} / \mathrm{M}^{2}$ ) CCNU $40 \mathrm{mg}$ orally and deep $x$-ray therapy to the whole head (1920 r/23 days). Two weeks after the onset of meningitis, he became paraplegic with retention of urine and developed a lump over the left temple. Bone scan showed a deposit in the mid-thoracic region and in the left and right temporo-orbital regions. He received palliative irradiation to the dorsal spine and left temple, but thereafter there was continuous deterioration in the haematological picture, hepatomegaly, and finally bronchopneumonia.

Necropsy findings revealed disseminated retinoblastoma which had spread to many organs including the bone marrow and spinal cord, with the notable exception of the brain. The tumour had recurred and filled the orbit, spreading also into the extraorbital optic nerve.

\section{Discussion}

The presence of malignant cells in the CSF is usually associated with an abnormal brain scan. However, in Case 5, the brain scan was normal and in retrospect one should have looked for tumour tissue in the spinal cord, since the lesion in the dorso-lumbar region was almost certainly present from the beginning and responsible for producing malignant cells in the CSF.
The necropsy of Case 6 was remarkable in that there were no intracranial metastases despite widespread dissemination elsewhere. It is assumed that the low dose of cranial irradiation had been effective whereas intrathecal methotrexate was not so successful.

As malignant meningitis due to retinoblastoma may not be clinically overt, it is suggested that all patients who have tumour spread along the optic nerve or orbital recurrence should have the CSF examined for malignant cells on several occasions, and a brain and cord scan. Once a patient has been found to have malignant cells in the CSF, radical treatment should be considered. This should comprise wide field cranial and spinal irradiation, together with cytotoxic therapy, at present intrathecal methotrexate combined with suitable systemic alkylating agents. Regular follow-up examination of the CSF is necessary as well as other follow-up measures. More attention should be given to the design of cytotoxic schedules intended to cross the blood-brain barrier.

It is clear that prolonged survival and perhaps cure (Case 4) can be attained even at a late stage of the disease.

\section{Summary}

Six patients with meningitis due to retinoblastoma are described. The diagnosis may be suspected on clinical examination but is made by the demonstration of malignant cells in the CSF. These patients have been treated with cranial irradiation together with systemic and intrathecal cytotoxic drugs. There is one survivor.

It is suggested that the CSF should be examined in all cases at risk so that the appropriate treatment can be started promptly and thus improve the prognosis.

Thanks are due to Dr J. G. Burger, Medical Superintendent, Groote Schuur Hospital, for his permission to publish this paper.

The follow-up of these cases was made possible by a grant from the Cancer Research Trust and the Radiotherapy Research Fund.

\section{References}

Berkeley, R. G., FUller, L. M., SEARs, M. E., and TAPley, N. DU v. (1967) In 'Cancer of the Head and Neck', ed.

W. S. MacComb and G. H. Fletcher, p. 408. Williams \& Wilkins, Baltimore

ifekwunigwe, A. e., PUlvertaft, R. J. v., and williams, A. O. (ig66) Brit. F. Cancer, 20, 250

KNAPP, H. (1869) Cited by Merriam (1950)

MERriam, G. R. (1950) Arch. Ophthal., 44, 7 I

REESE, A. B. (1963) 'Tumors of the Eye', 2nd ed., p. Ior. Harper \& Row, New York

SPRiggs, A. I., and Boddington, м. м. (1968) 'The Cytology of Effusions', 2nd ed., p. 48. Heinemann, London

wiEczoreK, v. (1964) Dtsch. Z. Nervenheilk., 186, 410 